\title{
French current practice for ambulatory anesthesia in children: a survey among the French-speaking Pediatric Anesthesiologists Association (ADARPEF)
}

\begin{tabular}{|r|l|}
\hline Journal: & Pediatric Anesthesia \\
\hline Manuscript ID: & PAN-2010-0293.R3 \\
\hline Wiley - Manuscript type: & Original Paper \\
\hline Date Submitted by the & 16 -Nov-2010 \\
\hline Complete List of Authors: & $\begin{array}{l}\text { Nivoche, Yves; Hôpital Robert Debré, Service d'anesthésie } \\
\text { réanimation } \\
\text { Lucas-Polomeni, MM; Service d'Anesthésie-Réanimation } \\
\text { Chirurgicale 2, Hôpital Pontchaillou } \\
\text { Dahmani, Souhayl; Robert Debre Hospital, Anaesthesiology } \\
\text { Brasher, Christopher; Robert Debré University Hospital, } \\
\text { Anaesthesia } \\
\text { Wodey, Eric; CHU Pontchaillou, Service d'Anesthésie Réanimation } 2 \\
\text { Courrèges, Philippe; Hôpital Jeanne de Flandre, Pôle d'Anesthésie } \\
\text { Réanimation }\end{array}$ \\
\hline Key Words: & $\begin{array}{l}\text { outpatient < Ambulatory, Audit, quality improvement < Outcomes, } \\
\text { children, pediatric anesthesia, Ambulatory }\end{array}$ \\
\hline
\end{tabular}


French current practice for ambulatory anesthesia in children: a survey among the Frenchspeaking Pediatric Anesthesiologists Association (ADARPEF)

Yves Nivoche MD¹, Marie-Madeleine Lucas $\mathrm{MD}^{2}$, Souhayl Dahmani MD ${ }^{1}$, Christopher Brasher $\mathrm{MD}^{1}$, Eric Wodey $\mathrm{MD}^{2}$, Philippe Courrèges $\mathrm{MD}^{3}$, French-speaking Pediatric Anesthesiologists Association (ADARPEF)

${ }^{1}$ Service d'Anesthésie Réanimation et de traitement de la douleur, Hôpital Robert Debré, Paris ${ }^{2}$ Service d'Anesthésie Réanimation II, Hôpital Anne de Bretagne, Rennes

${ }^{3}$ Pôle d'Anesthésie Réanimation, Hôpital Jeanne de Flandre, Lille

Correspondence to : ADARPEF, Dr Philippe Courrèges ,1417, rue Bataille 62840 Sailly sur la Lys, France e-mail: nppourreges@free.fr

Running tittle : Outpatient anesthesia 


\begin{abstract}
Background: This survey aims to describe current practice in ambulatory care among pediatric anesthesiologists in France.

Methods: Members of the French-speaking Pediatric Anesthesiologists Association (ADARPEF) were sent a questionnaire examining the proportion of pediatric ambulatory anesthesia practiced by each responder, the level of adherence to pediatric ambulatory anesthesia guidelines, and responder consensus in decision making when faced with common case scenarios in pediatric ambulatory anesthesia. For the latter, consensus was defined as a $>80 \%$ opinion.

Results: 145 pediatric anesthesiologists replied (43\%). Ambulatory anesthesia appears underused in France. Recent French pediatric ambulatory anesthesia guidelines are being applied. Post operative pain is poorly managed. The choice of scheduling children for ambulatory anesthesia appears to be more heavily influenced by practitioners' subjective evaluation than evidence from the literature.

Conclusion: A better commitment for ambulatory care must be found amongst anesthesiologists. Further studies are required to improve coherence, safety and efficiency of children selection for ambulatory anesthesia.
\end{abstract}

Key-words: children, pediatric anesthesia, outpatient procedures, ambulatory 


\section{Introduction}

Ambulatory pediatric anesthesia has substantial benefits over inpatient anesthesia, provided care is high quality and patient selection is appropriate. In 2008, experts from National Council of Pediatric Surgery (Conseil national de Chirurgie de l'Enfant : CNCE) and from the French-speaking Pediatric Anesthesiologists Association (Association des Anesthésistes Réanimateurs Pédiatriques d'Expression Française : ADARPEF) conjointly examined updated data on ambulatory pediatric surgery. Quality and safety guidelines regarding good anesthetic practice in patients aged $<18$ years scheduled for ambulatory procedures were drafted from the data. The guideline recommendations related to issues around having dedicated ambulatory care units, specific medical skills, patient selection and peri-operative management. These guidelines were field tested in a limited number of hospitals, approved by the CNCE and ADARPEF, officially adopted by the French Ministry of Health, and published electronically on both institutions' websites in May 2009 (1; 2). The guidelines defined ambulatory anesthesia as "every mode of planned anesthesia given by an anesthesiologist during a stay $<1$ day's duration".

Six months after e-publication, the ADARPEF performed a survey aiming to examine pediatric ambulatory anesthesia practice in France. The survey had two related aims: (i) determine the level of adherence to the above mentioned pediatric ambulatory anesthesia guidelines (ii) gather further information about what pediatric anesthesiologists thought were suitable cases for ambulatory anesthesia by eliciting clinician responses to theoretical case scenarios in pediatric ambulatory anesthesia.

\section{Materials and Methods}

In November 2009, 341 ADARPEF members, all of whom were practicing in France, were emailed a questionnaire that remained available on the ADARPEF web-site for a further month. Non-responding members were sent a reminder 15 days later.

The questionnaire was in 3 sections. The $1^{\text {st }}$ (table 1) inquired the practitioners' seniority, the proportion of their anesthesia activity that was pediatric, and, for children aged $<18$ years, their 
annual number and percentage of cases that were performed in ambulatory mode. The type of medical structure was defined (teaching/university, public, private, etc), as was the level of pediatric activity, and the presence or absence of dedicated pediatric surgery and day care units.

The $2^{\text {nd }}$ section (table 2) asked the lowest accepted age for ambulatory care, most commonly performed ambulatory procedures, and descriptions of peri-anesthetic management.

The $3^{\text {rd }}$ section (table 3 ) presented responders with 24 different pediatric anesthesia case-scenarios drawn up by the ADARPEF Scientific Committee. Scenarios presented common ambulatory procedures in children, with or without common or clinically important symptoms, illnesses, or preexisting co-morbidities. Symptoms and co-morbidities included asthma, diabetes mellitus, malignant hyperthermia susceptibility, morbid obesity, obstructive sleep apnea (OSA), sickle-cell disease, fever, signs of upper respiratory tract infection. Responders were asked for a yes/no response as to suitability for ambulatory care for each scenario. An $80 \%$ majority opinion was chosen as a consensus. A dedicated pediatric anesthesiologist was defined as one whose clinical practice included more than $50 \%$ of patients $<18$ years of age.

\section{Subjects studied}

Completed questionnaires were descriptively analyzed. Correlation between guidelines recommendations, responders' medical structures and peri-operative management was assessed. Responder consensus to proceed with ambulatory care for patients according to clinical case scenarios was analyzed.

Results (tables 1, 2, 3)

Only 145 of 341 members (43\%) replied over the one month period. All were included in analysis. Only 42 of a total of 3480 questions were left unanswered (1\%).

Almost $3 / 4$ of responders (72\%) were experienced pediatric anesthesiologists according to the study definition. Almost $1 / 2 \quad(47 \%)$ practiced exclusively in pediatrics, predominantly in university/teaching hospitals. Ambulatory anesthesia represented around $1 / 3$ of overall clinical practice and commonly involved imaging, endoscopic, orthopedic and ENT procedures. Over 90\% 
of responders reported practicing in structures with dedicated pediatric inpatient, pediatric surgery, and ambulatory care units as recommended by the guidelines.

Almost $60 \%$ of responders worked in units that hold regular meetings to discuss the pertinence of choices made between ambulatory and inpatient care in a selection of patients. This is recommended by the guidelines. These meetings assess whether the type of care chosen (ambulatory or hospitalization) was adapted to each patient given age, pathology and type of procedure. The aim is to improve future admission selection. Further, in accordance with the guidelines, 6 months was the predominant lowest acceptable age for ambulatory care in $43 \%$ of responders, and the majority of parents were given documentation describing the peri-operative period. A minority of responders (25\%) prescribed systematic anticipatory analgesia, and $1 / 3$ prescribed rescue analgesia.

Only $42 \%$ of case scenarios resulted in consensus for proceeding with or deciding against ambulatory care. One third resulted in 40 to $60 \%$ agreement - a strong lack of consensus.

\section{Discussion}

The results must be discussed in the light of the survey's limits: (i) most responders work predominantly in teaching/university hospitals, unrepresentative of the French ambulatory pediatric anesthesia as a whole, which is mainly ENT procedures in private clinics; (ii) the responder rate is low; this may be due partly to indifference for ambulatory mode, partly to the short survey duration, and partly to dedicated member practice in fields unconcerned by ambulatory pediatric anesthesia (Neurosurgery, Cardiac Surgery, Critical Care, Pain Medicine); (iii) case scenario descriptions were limited to yes/no responses which facilitated analysis but excluded many variables; (iv) sociofamilial or discharge criteria were not explored. Despite these weaknesses, the results described in this study probably do reflect pediatric anesthesiologists' practice in France.

Despite the advantages of ambulatory anesthesia for children, ambulatory care is underutilized in France. The overall ambulatory rate is lower than the $\geq 50 \%$ reported from many other countries (35). Children are generally well suited to ambulatory anesthesia, given the disturbance that 
hospitalization represents to them, and the relatively benign nature of many pediatric surgical procedures (6). With well managed pediatric ambulatory care, demonstrating expertise and building patient and parent confidence, more complex patients can also be managed in an ambulatory setting. Consequently, ambulatory care should be the preferred choice in children, and physicians should have to justify overnight hospitalization.

The main findings of the study were that most responders respect CNCE/ADARPEF guideline recommendations in terms of care structures, parent information and review of ambulatory care. Broadest agreement for a minimum age of pediatric ambulatory anesthesia also corresponds with guidelines. Low prescription rates of discharge analgesics are a major concern, previously reported elsewhere (4; 7). Subsequent fear of inadequate analgesia felt by children or parents may even reduce acceptance of ambulatory care.

Compared to other similar studies, the consensus rates to case scenarios asking whether patients were suitable for ambulatory care were low, although higher than in a similar Canadian study of 64 responders (8). One reason may be that the definition of an $80 \%$ majority opinion as consensus was more severe than the $65 \%$ used by the ASA, the $70 \%$ used in the Canadian study, and the $75 \%$ used in other surveys (9). To give an informed yes or no answer as to the appropriateness of ambulatory care, responders needed to be knowledgeable about the anesthetic complications of the pathologies described in case scenarios, and to allow for patient age and type of procedure. They also needed to know whether complications were likely to be immediate or delayed, the latter invoking caution.

Case scenarios responses indicate that practitioners are more likely to decide upon ambulatory care subjectively rather than using evidence in the literature. For instance, the fact that diabetes mellitus is not a predictor of increased morbidity in pediatric anesthesia, provided that peri-operative fasting is reduced $(10 ; 11)$, does not seem well known. There seems little other explanation for the incoherence of results in two case scenarios involving diabetes mellitus with consensus for ambulatory care in a diabetic child scheduled for inguinal hernia repair, but complete lack of consensus for the simpler myringotomy and tube placement. Similar conclusions may be drawn as 
to lack of knowledge regarding the fact that ambulatory anesthesia does not increase the risk of developing a malignant hyperthermia in patients with malignant hyperthermia susceptibility (1012). The only consensus found in three scenarios involving malignant hyperthermia susceptibility was that against ambulatory care in the context of fever of $38^{\circ} \mathrm{C}$ and strabismus repair, and the fever may well have influenced the consensus against ambulatory care as much as malignant hyperthermia susceptibility. Nor was there was consensus for ambulatory care in a scenario involving isolated morbid obesity, despite the lack of evidence that it increases unanticipated admission rates following ambulatory care in children, or that inpatient care improves outcomes. This may be due to extrapolation of data describing predominantly respiratory peri-operative complications in obese adults undergoing ambulatory anesthesia (10).

The survey did not identify consensus on the subject of fever, whether in isolation or associated with co-morbidities. This is unsurprising as the literature is unhelpful on this subject. Similarly, no consensus was found for children with active or recent upper respiratory tract infections. Although increased peri-operative respiratory complications are observed in these contexts $(13 ; 14)$, baseline respiratory complication rates are low, uncommonly associated with serious morbidity (15) and unaffected by the mode of anesthetic practices (16).

There was no consensus for or against ambulatory care for a toddler with OSA undergoing circumcision. In contrast, OSA related morbidity in ENT patients seems well known, resulting in consensus against ambulatory anesthesia. Indeed, OSA clearly increases peri-operative risk and requires caution, particularly when associated with ENT surgery. OSA remains the most frequent indication for unexpected readmission after tonsillectomy (17), although no increase in post tonsillectomy complications has been demonstrated prospectively. A higher incidence of postoperative respiratory complications requiring medical intervention has also been retrospectively found in children with OSA aged $<2$ years (18). Accordingly, the American Academy of Pediatrics recommends inpatient mode for children with OSA aged $<36$ months, and all children with severe OSA (19), while the French Society of Anesthesia and Intensive Care (Société Française 
d'Anesthésie et de Réanimation : SFAR) and the ADARPEF both recommend inpatient care for tonsillectomies in children with severe OSA (20).

The recent literature on sickle-cell disease and pediatric ambulatory care is limited to 1 paper claiming that specific high risk situations including anesthesia requires "adequate responses" (21). Responders reported consensus against ambulatory anesthesia in a child with $58 \% \mathrm{HbS}$ scheduled for adeno-tonsillectomy \& bilateral myringotomy and tube placement.

No consensus was found for cases involving isolated unclassified encephalopathy and minor laparoscopic surgery in a toddler (the latter probably too uncommon given the patient's age). There was however consensus to proceed with ambulatory anesthesia in scenarios involving aggressive autism, Lowe's syndrome (a rare disease seemingly known to responders despite 7 non-responses), and an adolescent given non-steroidal anti-inflammatories the day before an arthroscopy. Consensus was also found against an asthmatic child having suffered an attack the day before adenotonsillectomy.

In summary, although the literature is often unhelpful in deciding for or against ambulatory care, pediatric anesthesiologists also seemed uninformed about the information that does exist. Despite studies showing that peri-operative surgical complication rates are higher than those related to previous medical conditions (22), lack of knowledge with respect to specific pathologies and their impact upon risk in ambulatory anesthesia seems to hinder the employment and development of ambulatory pediatric anesthesia. The findings from this section of the survey imply more education is needed in determining suitability for pediatric ambulatory surgery. Although life-threatening complications are rare in ambulatory pediatric anesthesia, indications for inpatient care should be systematically reviewed using relevant journals, and cross-referenced with morbidity/mortality studies in order to improve patient selection criteria and peri-operative management and reduce unnecessary hospitalizations. However, although there is room for education for cases where there is good evidence, the majority of non-consensual scenarios involved situations for which the literature is ambiguous implying opinions vary and thus it would be inappropriate to proscribe 
practice in these situations. In these scenarios, further studies are required in the field of pertinent complications, their incidence, and associated risk factors.

Fear of ambulatory care planning failure seems to negatively influence care providers. Failure and cancellation have consequences, including the economic and emotional impact upon children and parents (23), surgical team underemployment, and futile administrative effort. A balance needs to be found, maximizing the use of ambulatory care for appropriate patients, while scheduling inpatient care for patients with risk factors for complications requiring hospitalization, thus avoiding the costs and stress associated with unplanned admissions.

\section{Conclusion}

Despite its limits, this survey reveals that ADARPEF members practicing in France: (i) in general follow French CNCE/ADARPEF guideline recommendations, but, (ii) do not sufficiently use ambulatory anesthesia in children, (iii) prescribe post-operative analgesics poorly, and (iv) generally demonstrate lack of consensus as to the appropriateness of ambulatory care in common clinical situations.

More information must be provided to pediatric anesthetists to improve the quality and use of ambulatory pediatric anesthesia.

\section{References}

1. Léculée R, Courrèges P. À propos des recommandations du Conseil National de la Chirurgie de l'Enfant (CNCE) et de l'ADARPEF sur la chirurgie ambulatoire de l'enfant de moins de 18 ans. Ann Fr Anesth Reanim 2010; 29: 552-3

2. Léculée $\mathrm{R}$, Courrèges $\mathrm{P}$. Chirurgie ambulatoire de l'enfant de moins de 18 ans : recommandations. Arch Pediatr 2010; 17: 844-5

3. De Lathouwer C, Poullier JP. How much ambulatory surgery in the World in 1996-1997 and trends? Ambul Surg. 2000; 18: 191-210

4. Segerdahl M, Warrén-Stomberg M, Rawal N et al. Children in day surgery: clinical practice and routines. The results from a nation-wide survey. Acta Anaesthesiol Scand 2008; 52:821- 
5. Rabbitts JA, Groenewald CB, Moriarty JP et al. Epidemiology of Ambulatory Anesthesia for Children in the United States: 2006 and 1996. Under publication. Anesth Analg 2010

6. SFAR. Recommandations formalisées d'experts. Prise en charge anesthésique des patients en hospitalisation ambulatoire. Ann Fr Anesth Reanim. 2010; 29: 67-72

7. Fortier M, MacLaren JE, Martin SR et al. Paediatric pain after ambulatory surgery: where's the medication? Paediatrics 2009; 124: 588-95

8. Abu-Shahwan I. Ambulatory anaesthesia and the lack of consensus among Canadian paediatric anaesthetists: a survey. Paed Anaest 2007; 17: 223-9

9. Silverstein JH, Apfelbaum JL, Barlow JC et al. Practice guidelines for postanesthetic care. A report by the American Society of Anesthesiology Task Force on postanesthetic care. Anesthesiology 2002; 96: 742-52

10. Bryson GL, Chung F, Cox RG, et al. Canadian Ambulatory Anaesthesia Research Education group. Patient selection in ambulatory anaesthesia - an evidence-based review: part II. Can J Anaesth. 2004; 51: 782-94

11. Chung F, Mezei G, Tong D. Pre-existing medical conditions as predictors of adverse events in day-case surgery. Br J Anaesth 1999; 83: 262-70

12. Yentis SM, Levine MF, Hartley EJ. Should all children with suspected or confirmed malignant hyperthermia susceptibility be admitted after surgery? A 10 year review. Anesth Analg 1992; 75: 345-50

13. Tait AR, Malviya S, Voepel-Lewis T et al. Risk factors for perioperative adverse respiratory events in children with upper respiratory tract infections. Anesthesiology 2001; 95: 299- 306

14. von Ungern-Sternberg BS, Boda K, Chambers NA et al. Risk assessment for respiratory complications in paediatric anaesthesia: a prospective cohort study. Lancet. 2010 4; 376: 773-83

15. Jimenez N, Posner KL, Cheney FW, Caplan RA et al. An update on pediatric anesthesia 
liability: a closed claims analysis. Anesth Analg. 2007; 104: 147-53

16. Warner DO, Warner MA, Barnes RD et al. Perioperative respiratory complications in patients with asthma. Anesthesiology 1996; 85: 460-7

17. American Thoracic Society. Cardiorespiratory sleep studies in children: establishment of normative data and polysomnography predictors of morbidity. Am J Respir Crit Care Med 1999; 160: 1381-7

18. Wilson K, Lakheeram I, Morielli A et al. Can assessment for obstructive sleep apnea help predict posttonsillectomy respiratory complications? Anesthesiology 2002; 96: 313-22

19. American academy of paediatrics. Clinical practice guideline: diagnosis and management of childhood obstructive sleep apnea syndrome. Paediatrics 2002; 109: 704-12

20. Orliaguet G. Anaesthesia for tonsillectomy in children. Ann Fr Anesth Reanim. 2008; 273: 200-1

21. Marchant WA, Walker I. Anaesthetic management of the child with sickle cell disease. Paediatr Anaesth. 2003; 13: 473-89

22. Lermitte J, Chung F. Patient selection in ambulatory surgery. Curr Opin Anaesthesiol. 2005; 18: $598-602$

23. Tait AR, Voepel-Lewis T, Munro HM et al. Cancellation of pediatric outpatient surgery: economic and emotional implications for patients and their families. J Clin Anesth. 1997; 9: 213-9 
Table 1: Practitioner details (no unanswered questions in all 145 responses; bold characters $=$ majority)

$\begin{array}{lcr}\text { ADARPEF members } & 92 \% \\ \text { Years of pediatric anesthesia practice (mean } \pm \text { SD) } & 15 \pm 2 & \\ \mathrm{~N}^{\circ} \text { of children }<18 \text { yo. anesthetized / yr (mean } \pm \text { SD) } & 742 \pm 103 & \\ \% \text { of practice in children } & >50 \% & \mathbf{4 7 \%} \\ & <50 \% & 25 \% \\ & \text { occasional } & 25 \% \\ & 0-10 \% & 3 \% \\ \text { Children outpatient } \% \text { rate } & 10-25 \% & 9 \% \\ & 25-50 \% & \mathbf{3 2 \%} \\ & 50-75 \% & 27 \% \\ & 75-100 \% & 8 \% \\ \text { Employing medical structure } & \text { University } & 17 \% \\ & \text { General } & 9 \% \\ \text { Private hospital } & 15 \% \\ \text { Identified pediatric inpatient unit (Yes) } & \text { Private clinic } & \\ \text { Identified pediatric surgery unit (Yes) } & 92 \% & \\ \text { Identified day-care unit (Yes) } & 96 \% & \end{array}$


1

2

3

4

5

6

7

8

9

10

11

12

13

14

Table 2: Anesthetic practice (1 responder did not answer the routine ambulatory procedure question; bold characters $=$ majority)

$\begin{array}{lll}\text { Regular meetings for retrospective } & \text { Yes } & \mathbf{5 8} \\ \text { analysis of hospitalization modes } & \text { No } & 17 \% \\ & \text { Unknown } & 25 \% \\ \text { Lowest age for routine ambulatory care } & <1 \text { mo } & 4 \% \\ & 1 \text { mo } & 4 \% \\ & 6 \text { mo } & \mathbf{4 3 \%} \\ & 6 \text { mo-1yr } & 19 \% \\ \text { Routine ambulatory procedures } & \text { Other } & 13 \% \\ & \text { Diagnostic (RMI, endoscopy...) } & \mathbf{8 5 \%} \\ & \text { Visceral } & 76 \% \\ & \text { Urology } & 85 \% \\ & \text { Orthopedics } & \mathbf{8 3 \%} \\ & \text { Cosmetics } & 65 \% \\ \text { Rescue analgesic prescription } & \text { Tonsillectomy } & 31 \% \\ & \text { Adenoidectomy } & 78 \% \\ \text { Preoperative written information } & \text { Myringotomy + tube } & 79 \% \\ & \text { Others } & 26 \% \\ & \text { Yes } & \mathbf{9 0 \%} \\ & \text { No } & 10 \%\end{array}$


Table 3: Case scenarios $($ bold characters $=$ consensus $)$

2

3 Isolated pre-existing co-morbidity

(20)

4 Age Pre-existing Disease

$615 \mathrm{yr}$ Aggressive autism

77 yr Lowe's syndrome

8

$95 \mathrm{yr}$ Diabetes mellitus

10

$11^{4} \mathrm{yr}$ Sickle cell disease $(\mathrm{HbS}$

$58 \%$ )

12

OSA

133

$15^{12}$ yr Morbid obesity

$167 \mathrm{yr}$ Diabetes mellitus

$175 \mathrm{yr} \quad$ Unclassified encephalopathy

Procedure

RMI

Ocular examination

Inguinal hernia repair

Adeno-tonsillectomy+bilat. $12 \%$ myringotomy/tube

Adeno-tonsillectomy

Bilat. myringotomy/tube

Bilat. myringotomy/tube

Endoscopic gastrostomy

Circumcision

Bilat. myringotomy/tube

$\begin{array}{lll}\text { Yes } & \text { No } & \text { Unanswered (n) } \\ \mathbf{9 7 \%} & \mathbf{3 \%} & \mathbf{0} \\ \mathbf{8 4 \%} & \mathbf{1 6 \%} & \mathbf{7}\end{array}$

$192 \mathrm{yr}$ OSA

2118 mo Malignant hyperthermia $22 \quad$ susceptibility

23 Symptoms \& specific situations, without pre-existing co-morbidity

2
2
2
2
2
2
3
3
3
3
3
3
3
3
3
3
4
4
4
4
4
$4 !$
4
4
4
4
5
5
5
5
5
5
5
5

Fever Rhinorrhoea Procedure

No No

38 c Purulent

Knee arthroscopy

Adeno-tonsillectomy+bilat. $11 \%$ myringotomy/tube

$\begin{array}{llll}\text { Adeno-tonsillectomy } & 9 \% & \mathbf{9 1 \%} & 2\end{array}$

Laparoscopic orchidopexy $\quad 77 \% \quad 23 \% \quad 3$

Urological endoscopy $\quad 54 \% \quad 46 \% \quad 4$

Myringotomy/tube

$70 \% \quad 30 \% \quad 1$

$38^{\circ} \mathrm{C} \quad \mathrm{No}$

$38^{\circ} \mathrm{C} \quad$ Clear

$38^{\circ} \mathrm{C} \quad$ No

Inguinal hernia repair

Inguinal hernia repair

$49 \%$

$51 \% \quad 1$

$45 \% \quad 55 \% \quad 2$

${ }_{9}$ Symptoms combined with pre-existing co-morbidity

40Age Pre-existing Disease

Fever Rhinorrhoea

Procedure

No Clear

$38^{\circ} \mathrm{c} \quad$ No

Inguinal hernia repair

Strabismus

Yes No

Unanswered (n)

310 yr Malignant hyperthermia susceptibility

$45_{12}$ yr Morbid obesity

8

Malignant hyperthermia susceptibility

92 yr Asthma

$51^{2}$ yr Asthma

$38^{\circ} \mathrm{C} \quad$ No

$38^{\circ} \mathrm{C} \quad$ No

Myringotomy/tube

Myringotomy/tube

$38^{\circ} \mathrm{C} \quad$ No

No Purulent
Myringotomy/tube

RMI
$92 \% \quad 8 \% \quad 1$

$19 \% \quad 81 \% \quad 0$

$38 \% \quad 62 \% \quad 1$

$29 \% \quad 71 \% \quad 1$

$53 \% \quad 47 \% \quad 2$

$48 \% \quad 52 \% \quad 2$ 